\title{
Soundproofing Wall: A Review
}

\author{
Fitria Hidayanti, Kiki Rezki Lestari, Alvin Liyanto \\ Engineering Physics Department, Universitas Nasional, Jakarta 12520 Indonesia \\ fitriahidayanti@gmail.com
}

\begin{abstract}
This review paper will explain some of the results of research on the development of soundproofing wall technology. It was starting from the single-layer, double-layers, triple-layers soundproofing walls to have a sandwich structure. Sound Transmission Loss (STL) and Sound Absorption Coefficient (SAC) are the two biggest acoustic problems that must be solved in designing soundproofing walls. The selection of the right material and modifications that can be made possible to improve the performance of the soundproofing wall need to be done to overcome this problem, for example, flax fiber material which has a sound reduction efficiency of $21.2 \%$ with a thickness of $1 \mathrm{~cm}$. Apart from the choice of sound attenuation, modifications to the soundproofing wall need to be done to improve the performance of the material for example, wooden triple glazed window can reduce sound transmission (STL) by $36 \mathrm{~dB}$. Therefore, research on the type of material that has good acoustic properties and the right type of modification to be used in the soundproofing wall cannot be separated to create an optimal soundproofing wall.
\end{abstract}

Key words: Soundproofing, Single-layer, Double-layers, Triple-layers, Sound Transmission Loss, Sound Absorption Coefficient

\section{INTRODUCTION}

Sound insulation is also essential between rooms, and methods are known for achieving good efficiency. Building techniques and materials continue to develop, however, and there is an ongoing interest in improving construction, making it lighter, cheaper, simpler to build and more compact.

According to Ballagh in 2012, it was known that there was a limit to sound insulation that could be achieved with a single panel, most single panels obeyed the law of mass, and on a practical panel size of say, $500 \mathrm{~kg} / \mathrm{m}^{2}(200 \mathrm{~mm}$ concrete) with sound insulation around STC/Rw (weighted sound reduction index) $55-60 \mathrm{~dB}$ [1]. The traditional method for reducing low-frequency noise requires the use of heavy attenuation material and therefore offsets the increase in panel performance [2]. As a consequence, in modern buildings, transport vehicles, aerospace / aeronautical fuselages, double panel partitions are commonly used, which have superior sound insulation characteristics than single panel partitions.
Sound Transmission Loss (STL) and Sound Absorption Coefficient (SAC) of the panel are the two biggest acoustic problems for researchers in this field in the last few decades. The most interesting structure for sound transmission is a structure composed of many layers, one of which is a double-layered soundproofing wall and a sandwich layer [3, 4] which is a passive method for sound dampening $[5,6]$.

Major improvements can be achieved by using double panel construction with an air gap in between, even with relatively lightweight panels, performance up to STC $65+$ can be achieved for construction masses of around $50 \mathrm{~kg} / \mathrm{m}^{2}$. If multiple panels provide such an advantage, a triple panel construction (3 panels separated by 2 air gaps) would be better. Some examples of three-panel structures that have been used in practice include masonry walls with plasterboard layers mounted on battens on each side or triple glazing used in very cold climates where 3 glass panels are used with 2 air gaps, to maximize thermal insulation [1,7]. The opinions of Ballagh were also corroborated by the statements of Myong and Jin in 2019 which stated that the three-layer structure of sound dampening has a more convincing performance than the sound dampening wall with one panel or two-panelled $[8$, 9]. This happens because the sound waves that propagate through the wall are reflected according to the number of types of material used compared to using only one kind of panel $[10,11]$.

Sandwich panels, such as low density, high rigidity to mass ratio and excellent thermal and acoustic characteristics, can be engineered to have exactly the same characteristics as many panels, and have therefore been commonly used as soundproof concepts. For sandwich construction, there are many kinds of heart, such as air cavities, foam, honeycomb, and waves (folded plates), to name a few. Extensive research has been conducted to test STLs from different sandwich panels, which can be categorized by core form [3, 12].

\section{LITERATURE REVIEWS}

Sound dampening is a tool to reduce sound so that unwanted sounds are not heard or not clear. The basic principle of the performance of the sound dampening wall starts from the propagation of sound waves through a wall, sound waves entering the wall (I) will experience energy loss after passing through the wall (T), and the energy loss is sound waves 
reflected from the wall (R). The explanation can be described as follows:

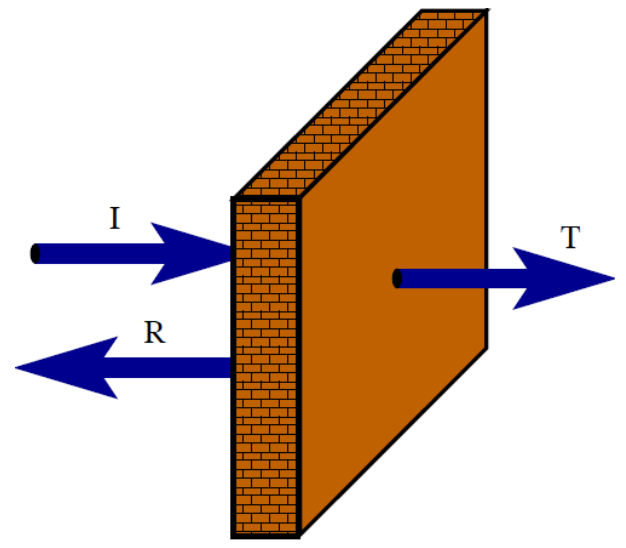

Figure 1: Sound propagation through walls [13]

From Figure 1, some of the sound wave energy is reflected as a result of the wall and because the wall has a finite mass, some of the sound wave energy is transmitted through the wall. The existence of these walls makes all three types of sound waves cannot have a pair of conditions directly. The wall can be assumed to have a thin thickness (thin against the wavelength of sound) and a very fast sound speed in a solid medium. This is the best assumption for all types of cases [13]. Therefore,

$$
\left(\frac{I-E}{\rho f}\right) e^{i \omega t}=u_{\text {wall }}=\left(\frac{T}{g e}\right) e^{j \omega t}
$$

From Equation (1), I is an incident wave or incoming sound wave, $\mathrm{R}$ is reflected wave or sound wave reflected from the wall, $\mathrm{T}$ is transmitted wave or sound wave that can still propagate after passing through the wall, $\rho$ is the density of the fluid (air), c is the speed of sound, $\omega$ is the angular frequency, and $t$ is time. The amount of sound wave energy that has passed through the wall $(\mathrm{T})$ will not have the same value compared to the energy of the wave source (I) because of the sound reflected, so to find out the amount of sound wave energy that is "lost" from input to output can be defined by the equation:

$$
\begin{gathered}
I_{\text {Lost }}--10 \log \left(\frac{|\pi|^{2}}{|\Gamma|^{2}}\right) \\
\mathrm{d}_{\text {Lost }}=10 \log \left(\begin{array}{c}
4\left(\mu \mathrm{r}^{2}\right. \\
\mathrm{m}^{2} \mathrm{cos}^{2}+4 \rho^{2} \mathrm{~s}^{2}
\end{array}\right)
\end{gathered}
$$

The Equation (2) and Equation (3) are equivalent, $m$ is mass of the wall of the broad union, and the equation is a numerator value, so it requires a negative sign to indicate that the value of the transmission of sound waves lost or $\mathrm{T}_{\text {Lost }}$ can be positive (Dupere, 2017). In addition, there are numerical calculations that have been done by Tageman in his research in 2013.

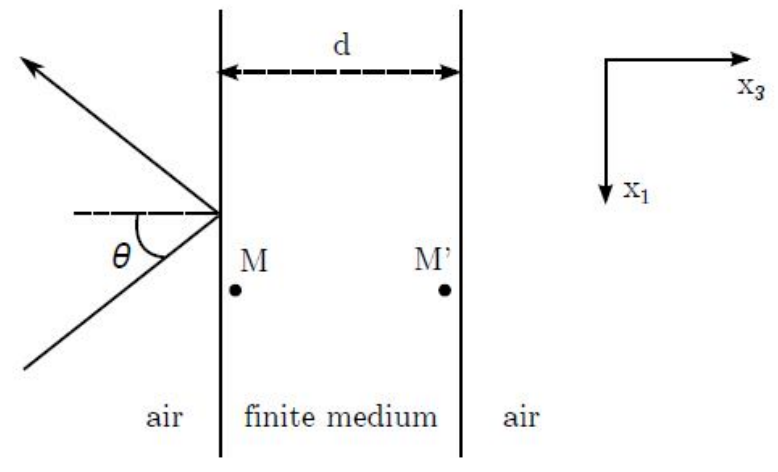

Figure 2: Illustration of sound wave propagation that overlaps a wall with thickness d, with incident angle $\theta$ [14]

Figure 2 illustrates the propagation of sound waves that hit walls with thickness $d$, at an angle $\theta$. The wall is in the $x_{1}$ and $\mathrm{x}_{2}$ directions. The incoming wave creates a wave field in the medium, where the $\mathrm{x}_{1}$ component of the wavenumber is the same as the $x_{1}$ component of the wavenumber in air, the $F_{\mathrm{a}} \sin \theta$ where $\mathrm{k}_{\mathrm{a}}$ is the wavenumber in free air. Sound propagation in layers is represented by the transfer matrix [T] so that:

$$
\boldsymbol{V}(M)=[\boldsymbol{T}] \boldsymbol{V}\left(M^{\prime}\right)
$$

From Equation (4), $M$ and $\mathrm{M}$ 'is the point given in illustration $1, \mathrm{~V}(\mathrm{M})$ is a vector variable that describes the acoustic linkup space that exists at point $\mathrm{M}$. Adopt $\mathrm{p}$ pressure and particle velocity $\mathrm{v}$ as state variables, the relationship between state variables of each side of the layer can be written as Equation (5):

$$
\left[\begin{array}{l}
p(M) \\
u_{3}(M)
\end{array}\right]=\left[\begin{array}{ll}
T_{11} & T_{12} \\
T_{21} & T_{22}
\end{array}\right]\left[\begin{array}{l}
p\left(M^{\prime}\right) \\
u_{3}\left(M^{\prime}\right)
\end{array}\right]
$$

It can be noted that the $\mathrm{x}_{3}$ component of the particle velocity is a state variable, i.e. the velocity to the surface of the layer. For isotropic and homogeneous layers, the following relationship applies in Equation (6) and Equation (7) (Song and Bolton, 2000):

$$
\begin{gathered}
T_{11}=T_{22} \\
T_{11} T_{22}-T_{21} T_{12}=1
\end{gathered}
$$

From the two equations above it can also be stated as a determinant $(\mathrm{T})$ or $\operatorname{det}(\mathrm{T})=1$, and because it is not zero, it can show that the transfer matrix cannot be reversed. For multi-layered structures, the relationship between state variables on the input and output sides is obtained by multiplying the transfer matrix of each layer (Crocker and Price, 1969), the explanation can be explained with a simple Equation (8), namely:

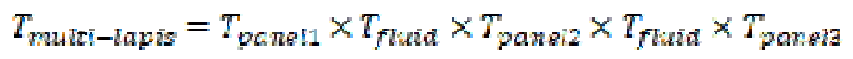


Fitria Hidayanti et al., International Journal of Emerging Trends in Engineering Research, 8(9), September 2020, 5408 - 5412

The transmission factor (FT) of a structure is defined as the ratio of the power transmitted and the strength that occurs. Sound power (W) can be written as:

$$
W-\frac{1}{2}(p v)
$$

Equation (9) can also be related to the characteristic impedance $(\mathrm{Zc}=\mathrm{p} / \mathrm{v})$, so that the equation can be written as:

$$
w=\frac{1}{2}\left(p^{2} / Z_{r}\right)
$$

The insertion of Equation (10) in the transmission factor definition produces a new equation:

$$
F_{T}-\frac{F_{T}^{2}\left\{1 / z_{C_{2}}\right]}{F_{i}^{7}\left\langle 1 / z_{r: 1}\right)}
$$

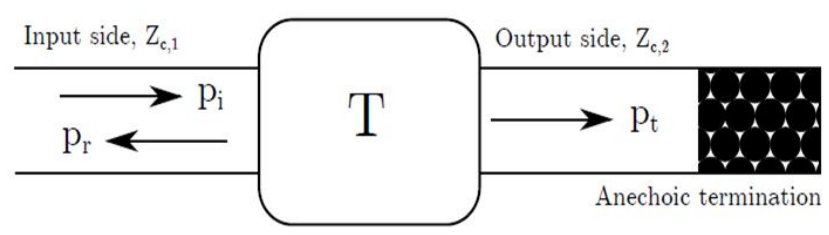

Figure 3: A system with a transfer matrix $T$, with pressure fields $p_{i}+$ $\mathrm{p}_{\mathrm{r}}$ on the input side, and $\mathrm{p}_{\mathrm{t}}$ on the output side [14]

From Equation (11), $Z_{c, 1}$ and $Z_{c, 2}$ are represented as successive input and output impedance characteristics, the values of these variables are real numbers. $p_{i}$ and $p_{i}$ is the output (transmissivity) and input (incident) sound pressure. This can be illustrated in Figure 3, where the symbol $\mathrm{T}$ in the picture is a matrix transfer function in a structure in Equation (12):

$$
\left[\begin{array}{l}
p_{1} \\
v_{1}
\end{array}\right]=\left[\begin{array}{ll}
T_{11} & T_{12} \\
T_{21} & T_{22}
\end{array}\right]\left[\begin{array}{l}
p_{2} \\
v_{2}
\end{array}\right]
$$

Pressure in Equation (13) and velocity in Equation (14) on the input side as well as pressure in Equation (15) and speed in Equation (16) on the output side are written as is

$$
\begin{gathered}
p_{1}=p_{i}+p_{r} \\
v_{1}=p_{1}-n_{z} \\
z_{c_{r} 1} \\
p_{2}=p_{t} \\
v_{1}=p_{t} / Z_{c, 2}
\end{gathered}
$$

Combining Equations (13) and Equation (14) results in:

$$
p_{i}=\left(p_{1}+v_{1} Z_{c, 1}\right) / 2
$$

Inserting Equation (17) into the matrix transfer function equation in Equation (12) results in:

$$
p_{i}=\left(T_{11} p_{2}+T_{12} v_{2}+Z_{c_{1} 1}\left(T_{21} p_{2}+T_{22} v_{2}\right)\right) / 2
$$

Express the pressure and speed variables on the output side, so Equation (18) can be changed to:

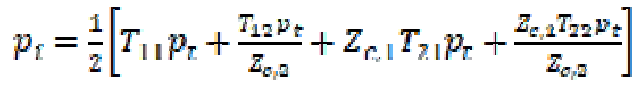

After reducing the incident pressure (pi), the next step is to enter Equation (19) into the transmission factor Equation (11), so that the equation can be changed to Equation (20):

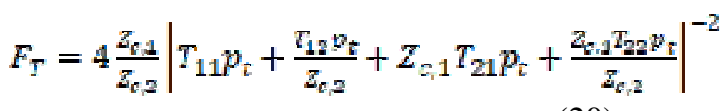

\section{RESULTS AND DISCUSSION}

The results of research conducted by Uris in 2006 [15] have shown the sound reduction index for frequencies at and below the resonant frequency (about $170 \mathrm{~Hz}$ ) is reduced by adding a gypsum board layer in the middle of a double frame partition since the inner layer decreases the depth of the cavity partition and then the triple leaf partition works like a single leaf partition with a mass equal to the sum of a single leaf mass. In most situations, the weighted sound reduction index is regulated by the $100-200 \mathrm{~Hz}$ band, since the introduction of the gypsum board layer in the center of the double frame causes a significant decrease in the weighted sound reduction index, which can be as high as 7-8 $\mathrm{dB}$, the insertion of the gypsum board layer in the center of the double frame causes a noticeable decrease in the weighted sound reduction index, which can be as high as 7-8 dB. This degradation is greater than that obtained when the effect of penetration around the electrical outlet box is evaluated. Therefore, a simple parameter model for the construction of a three-layer panel wall from Ballagh in 2012 was developed. Three masses (panels) connected by two springs (air holes) consist of this model. Two resonant frequencies are expected by the model, which will yield two decreases in sound transmission loss. Comparisons with available experimental data show a good agreement on the low frequency between estimated and measured performance for various constructs. The findings are explained in his scientific paper, where it can be shown that at higher frequencies, the three panel method has superior efficiency, but its efficiency is much lower at low frequencies. There are resonant frequencies of $93 \mathrm{~Hz}$ and $161 \mathrm{~Hz}$ in the three-panel configuration, and a $12 \mathrm{~dB}$ sound reduction at 100 Hz.

Berardi and Iannace in 2015 with the same material having a sound attenuation coefficient of 0.5 with a thickness of 100 $\mathrm{mm}$. In addition to cardboard material, research conducted by Berardi and Iannace also uses materials made from wood fiber $(6 \mathrm{~cm})$, hemp $(3 \mathrm{~cm})$, coconut fiber $(5 \mathrm{~cm})$, and sheep's hair (4 $\mathrm{cm})$ with successive sound attenuation coefficient values according to $0.6,0.4,0.5$, and 0.55 [16-18].

Then, the results of research conducted by Yang in 2015 [19-21] focused on three types of fiber glass sandwich structures to identify optimal sound insulation structures. Resistivity of glass fiber felt air flow is $6633 \mathrm{~Pa} . \mathrm{s} / \mathrm{m}^{2}$ (Loose), 
Fitria Hidayanti et al., International Journal of Emerging Trends in Engineering Research, 8(9), September 2020, 5408 - 5412

19579 Pa.s $/ \mathrm{m}^{2}$ (Mid) and 42724 Pa.s $/ \mathrm{m}^{2}$ (Dense), respectively. Three types of sandwich structures are Dense-Mid-Loose (DML), Mid-Loose-Dense (MLD) and Loose-Dense-Mid (LDM). The sound transmission loss is measured by the system of the impedance tube and the structure morphology studied by an optical microscope. The findings showed that the property of the sound insulation is affected by the direction of sound events and the composite structure. The ideal configuration of the sandwich is MLD with the incident surface. Composite structures with the best and worst sound insulation compared to $630 \mathrm{~Hz}, 1000 \mathrm{~Hz}$, $2000 \mathrm{~Hz}$ and $3000 \mathrm{~Hz}$. The growth rate of sound insulation respectively was $7.4 \%, 19.0 \%, 15.4 \%$ and $10.5 \%$.

Furthermore, the results of a study from Miskinis in 2016 analyzed the acoustic characteristics of wooden triple glazed windows used in sustainable energy-efficient buildings in the Baltic Sea region. Sound insulation measured from the two types of windows is very similar (the difference is up to $2 \mathrm{~dB}$ ). The Rw and SW window EU values vary from 32 to $35 \mathrm{~dB}$ and from 34 to $36 \mathrm{~dB}$, respectively. $\mathrm{Rw}+\mathrm{Ctr}$ values vary in the range of 28-30 $\mathrm{dB}$ (4-5 dB reduction compared to $\mathrm{Rw}$ ) for $\mathrm{SW}$ and in the range $28-31 \mathrm{~dB}(5-7 \mathrm{~dB}$ reduction compared to $\mathrm{Rw}$ ) for the EUW window. This shows that the type of window in this case does not have a significant impact on sound insulation because it is mainly dependent on the Insulated Glass Unit (IGU) [22].

The soundproof properties of polycarbonate (PC)/nano clay and $\mathrm{PC} /$ nano-silica nanocomposites that were tested through experiments were then analyzed in the results of research conducted by Sabet in 2017. By means of direct heat compression molding, nanocomposite sheets with a thickness of $3 \mathrm{~mm}$ are created. Twin screw extruders insert the nano clay and nano-silica particles into the PC matrix. Transmission electron microscopy examined the dispersion efficiency of 1,3 , and 5 percent by weight of nano clay and nano-silica in the PC matrix. To determine the mechanical properties of nanocomposites, dynamic mechanical analysis is conducted. Sound transmission loss (STL) is measured using impedance tubes in the $1600-6300 \mathrm{~Hz}$ frequency range and then used to describe nanocomposite sound controls. To model the loss of sound propagation in the impedance test tube, the finite element model was newly developed. The results showed that in the stiffness control area (1600-3600 $\mathrm{Hz}), \mathrm{PC} / 3$ percent by nano clay weight and 3 percent by nano-silica nanocomposite weight had a mean maximum increase of 5.5 and $6 \mathrm{~dB}$ in STL values, respectively. PC/3\% by weight of nano clay and $\mathrm{PC} / 3 \%$ by weight of nano-silica nanocomposites, on the other hand, have the same sound insulation properties in the $1600-3600 \mathrm{~Hz}$ frequency range [23-26].

Finally, the results of the next Karuppiah and Ramiah research in 2017 have a research objective, which is to find natural fiber materials that are environmentally friendly and inexpensive, such as jute fiber, as an effective substitute for synthetic materials, such as gypsum and foam. The material chosen is widely used in other industries, but no direct comparison has been made to evaluate which material is the best at absorbing sound. Their results show that among synthetic materials and fibers, jute fiber is the best performing: hemp with a thickness of $1 \mathrm{~cm}$ can absorb sound intensity of $21.2 \%$ with STL $14 \mathrm{~dB}$ at $400 \mathrm{~Hz}$ sound frequency compared to without using soundproofing walls and $12.57 \%$

\section{CONCLUSION}

In summary, there have been many developments that have been made for soundproofing walls starting from the selection of suitable material to be used as sound dampers as jute fiber material which can absorb sound intensity of $21.2 \%$ with STL $14 \mathrm{~dB}$ at $400 \mathrm{~Hz}$ sound frequency compared to without using soundproof walls and $12.57 \%$ more efficient than Gypsum material with the same thickness. Furthermore, the modification of the soundproofing wall which has a structure of more than one type of panel or material (such as double-layered, triple-layers, or sandwich structure) has better performance than the use of a single-layer structured soundproofing wall as the use of wooden triple glazed windows can reduce sound transmission (STL) up to $36 \mathrm{~dB}$. Therefore, to design the best performance soundproofing wall, a researcher and engineer must co-operate to analyze the material that will be used for the soundproofing wall of one panel and the type of modification that is very appropriate to use using that material.

\section{REFERENCES}

1. Ballagh, K., Sound Transmission through Triple Panel Walls - Low Frequency Model. Wellington, New Zealand, s.n. 2012.

2. Xin, F. X. and Lu, T. J.,. Analytical modeling of sound transmission through clamped triple-panel partition separated by enclosed air cavities. European Journal of Mechanics A/Solids, Volume 30, pp. 770 - 782, 2011.

3. Meng, H., Galland, M. A., Ichchou, M., Bareille, O., Xin, F. X., \& Lu, T. J.. Small perforations in corrugated sandwich panel significantly enhance low frequency sound absorption and transmission loss. Composite Structures, pp. 1 - 11, 2017.

4. Hidayanti F., Wati E.K., and Miftahudin M. F. Design of Energy Harvesters on Motorcycle Exhaust using Thermoelectric Generator for Power Supply Electronic Device. International Journal of Renewable Energy Research. 10(1), 251 - 259. 2020.

5. Shen, C., Zhang, H. and Liu, Y. Analytical modelling of sound transmission loss across finite clamped triple-wall sandwich panels in the presence of external mean flow. Applied Mathematical Modelling, Volume 73, p. 146-165, 2019. 
Fitria Hidayanti et al., International Journal of Emerging Trends in Engineering Research, 8(9), September 2020,5408 - 5412

6. Hidayanti F., Lestari K.R., and Anwar R. Arduino Based Conductive Silver Lamination Device. International Journal of Emerging Trends in Engineering Research. 8(2), 265 - 270. 2020.

7. Hidayanti F., Wati E.K., and Akbar H. Energy Harvesting System Design for Converting Noise into Electrical Energy. International Journal of Advanced Science and Technology. 29(03), 4791 - 4802. 2020.

8. Myong-Jin, K. Improving Sound Transmission Through Triple-Panel Structure Using Porous Material and Sonic Crystal. Archives of Acoustics, 44(3), pp. 533 - 541, 2019.

9. Hidayanti F., Rahmah F., and Wiryawan A. Design of Motorcycle Security System with Fingerprint Sensor using Ärduino Uno Microcontroller. International Journal of Advanced Science and Technology. 29(05), 4374 - 4391. 2020.

10. Oyelade, A. O., Sadiq, O. M. and Fakinlede, O. A. Sound transmission through triple plates separated by air cavities in the low-frequency range. Acta Mech, Volume 230, pp. 965 - 977, 2019.

11. Hidayanti F., Santoso H. H., and Amalia D. Induction Measurement of Extra High Voltage Air Duct. International Journal of Emerging Trends in Engineering Research. 8(4), 1424 - 1427. 2020.

12. Hidayanti F., Extraction of Limonite Nickel Ore of Tanjung Buli, Halmahera by Coal Roasting and Acid Leaching. International Journal of Mechanical and Production Engineering Research and Development. 10(2), 513 - 522, 2020.

13. Rabbani, V., Hodaei, M., Deng, X., Lu, H., Hui, D., and $\mathrm{Wu}, \mathrm{N}$. Sound transmission through a thick-walled FGM piezo-laminated cylindrical shell filled with and submerged in compressible fluids. Engineering Structures, 197, 109323, 2019.

14. Tageman, K., Modelling of sound transmission through multilayered elements using the transfer matrix method, Gothenburg: Chalmers University of Technology, 2013.

15. Uris, A., Bravo, J. M., Gomez-Lozano, V., Ramirez, P., and Llinares, J. Sound insulation of double frame partitions with an internal gypsum board layer. Applied Acoustics, 67(9), 918-925, 2006.

16. Berardi, U. and Iannace, G. Acoustic characterization of natural fibers for sound absorption applications. Building and Environment, pp. 1 - 13, 2015.

17. Hidayanti F., Development of Mercury Film Electrode for Cadmium Ion Determination using Voltammetry. International Journal of Advanced Science and Technology. 29(03), 5156 - 5163, 2020.

18. Hidayanti F., Rahmah F., and Septratama S. Design of Single-Axis Solar Tracker based on Arduino Uno Microcontroller. International Journal of Emerging Trends in Engineering Research. 8(4), 983 - 986, 2020.

19. Yang, Y., Chen, Z., Chen, Z., Fu, R., and Li, Y. Sound Insulation Properties of Sandwich Structures on Glass Fiber Felts. Fibers and Polymers, 16(7), pp. 1568 $-1577,2015$.
20. Hidayanti F., Rahmah F., and Sahro A. Mockup as Internet of Things Application for Hydroponics Plant Monitoring System. International Journal of Advanced Science and Technology. 29(05), 5157 - 5164. 2020.

21. Hidayanti F., Rahmah F., and Agusto J. Design of Solar Tracker on Solar Panel with Fresnel Concentrator. International Journal of Advanced Science and Technology. 29(05), 1014 - 1025. 2020.

22. Miskinis, K., Dikavicius, V. and Burlingis, A. The acoustic and thermal characteristics of wooden triple glazed windows. Noise Control Engr. J. 64, pp. 1 - 16, 2016.

23. Sabet, S. M., Keshavarz, R. and Ohadi, A. Sound isolation properties of polycarbonate/clay and polycarbonate/silica nanocomposites. Iranian Polymer Journal, Volume 27, pp. 57 - 66, 2017.

24. Hidayanti F., Rahmah F., and Ikrimah M. Dual-Axis Solar Tracking System Efficiency for Hydroponics Pump. International Journal of Emerging Trends in Engineering Research. 8(6), 2631 - 2634. 2020.

25. Hidayanti F., The Effect of Monocrystalline and Polycrystalline Material Structure on Solar Cell Performance. International Journal of Emerging Trends in Engineering Research. 8(7), 3420 - 3427. 2020.

26. Hidayanti F., Performance of Portable Battery Charger of Monocrystalline Solar Panel. International Journal of Emerging Trends in Engineering Research. 8(7), 3181 - 3184. 2020. 